\title{
Study of Ionized Magnesium and Calcium Levels in a Cohort of Patients with Septic Shock Treated with Standard Therapy and Antioxidants
}

\author{
Alfredo Aisa-Álvarez \\ American British Cowdray Medical Center IAP: Centro Medico ABC \\ María Elena Soto \\ Instituto Nacional de Cardiologia Ignacio Chavez \\ Gilberto Camarena-Alejo \\ American British Cowdray Medical Center IAP: Centro Medico ABC \\ Juvenal Franco-Granillo \\ American British Cowdray Medical Center IAP: Centro Medico ABC \\ Randall Cruz Soto \\ American British Cowdray Medical Center IAP: Centro Medico ABC \\ Israel Pérez-Torres \\ Instituto Nacional de Cardiologia Ignacio Chavez \\ Claudia Huesca Gómez \\ Instituto Nacional de Cardiologia Ignacio Chavez \\ Yazmín Estela Torres-Paz \\ Instituto Nacional de Cardiologia Ignacio Chavez \\ Giovanny Fuentevilla-Álvarez \\ Instituto Nacional de Cardiologia Ignacio Chavez \\ Ricardo Gamboa ( $\sim$ rgamboaa_2000@yahoo.com ) \\ Instituto Nacional de Cardiologia Ignacio Chavez https://orcid.org/0000-0001-9102-4240
}

\section{Research}

Keywords: lonized levels, septic shock, antioxidants

Posted Date: August 23rd, 2021

DOl: https://doi.org/10.21203/rs.3.rs-824191/v1

License: (9) (1) This work is licensed under a Creative Commons Attribution 4.0 International License. Read Full License 


\section{Abstract}

Background: Septic shock is the most serious form of sepsis and can be due to several factors, such as hypovolemia, vascular hyporesponsiveness, myocardial dysfunction, or dysfunction of the circulation. Likewise, electrolyte levels have been associated with septic shock in intensive care units, although it has been underdiagnosed. Based on this, the purpose of the present work was to evaluate plasma ionic levels in patients with septic shock before and after treatment with different antioxidants.

Methods: Plasma ionic levels were measured $\left(\mathrm{Na}^{+}, \mathrm{K}^{+}, \mathrm{Cl}^{-}\right.$and ionized $\mathrm{Ca}^{2+}$ and $\left.\mathrm{Mg}^{2+}\right)$ in 194 subjects, 129 healthy control patients, 14 patients with septic shock without treatment and 51 patients with septic shock under treatment with 4 different antioxidants (N-acetyl cysteine, melatonin, vitamin $\mathrm{C}$ and vitamin $\mathrm{E}$ ).

Results: We found important differences when comparing the plasma ionic levels of $\mathrm{K}^{+}, \mathrm{Ca}^{2+}$ and $\mathrm{Mg}^{2+}$ between the control group versus in both groups with sepsis at the time of hospital admission. In patients with septic shock, there is a decrease in the serum levels of ionized $\mathrm{Na}^{+}, \mathrm{K}^{+}, \mathrm{Cl}^{-}$and $\mathrm{Ca}^{2+}$ and $\mathrm{Mg}^{2+}$. Antioxidant treatment as an adjunct to the standard management of patients with septic shock increases the electrolyte deficit. The correction of the magnesium deficit also leads to an increase in serum calcium and potassium levels.

Conclusion: The management of antioxidant therapy in patients with septic shock within the first hours of admission can help to improve their ionic levels of $\mathrm{Ca}^{2+}$ and $\mathrm{Mg}^{2+}$, mainly in patients with lung damage.

Clinical Trial gov registration: NCT03557229. Registered june 14, 2018. https://clinicaltrials.gov/ct2/show/NTC03557229? term=alSA+ALFREDO\&draw $=2 \&$ rank $=1$

\section{Introduction}

Sepsis and septic shock are public health problems worldwide and represent a high cost to health systems; three cases have been reported for every 1000 inhabitants and 2.6 cases for every 100 hospital discharges, of which $51 \%$ receive medical attention in an intensive care unit and $17.3 \%$ in an intermediate or coronary care unit [1]. Septic shock is the most severe form of sepsis and occurs when it is associated with hypotension and tissue hypo perfusion. Locally, during hypo perfusion some organs can be compromised due to the redistribution of flow from the splanchnic and peripheral circulation to other sites. Hypotension and hypo perfusion associated with septic shock can be due to various factors such as hypovolemia, vascular hyporesponsiveness, myocardial dysfunction, or dysfunction in the circulation. On the other hand, electrolyte levels associated with septic shock in intensive care units have been underdiagnosed. There are reports [2] that correlate serum magnesium levels $\left(\mathrm{Mg}^{2+}\right)$ with the admission of patients to the Intensive Care Unit (ICU), the duration of their stay in the ICU, the requirement and duration of mechanical ventilator support, and the final outcome of the patient (discharge/death) [3].

The incidence of hypomagnesemia is reported in $2 \%$ of the general population, between $10-20 \%$ in hospitalized patients, and $50-60 \%$ in patients in an intensive care unit [4]. The magnesium concentration in plasma is kept in a narrow range between 1.7 and $2.2 \mathrm{mg} / \mathrm{dl}(0.75-0.95 \mathrm{mmol}$ or $1.5-1.9 \mathrm{mEq} / \mathrm{L})$, this homeostasis of magnesium depends on the balance between its intestinal absorption and its renal excretion [5]. Another electrolyte recognized as a factor in sepsis is the calcium [6]. The calcium exists in three forms or fractions in plasma o serum: ionized (iCa, free calcium) only this fraction is physiologically active, quelated (bound to phosphate, bicarbonate, citrate) and bound to protein. The Vitamin D deficiency, "relative" hypoparathyroidism, vitamin D resistance, and 1a hydroxylase deficiency are proposed mechanisms for hypocalcemia in critically ill patients [7]. The normal plasma calcium concentration is between 8.5 and $10.4 \mathrm{mg} / \mathrm{dl}$ and practically does not vary with age during childhood and adolescence. Normal ionic calcium concentrations are between 4.4 and $5.2 \mathrm{mg} / \mathrm{dl}(1.1-1.3 \mathrm{mmol} / \mathrm{l})$ [8]. Studies carry out in animals demonstrated that interleukin $1 \beta$ induces hypocalcemia in association with a decrease in parathyroid hormone (PTH) and an increase in the expression of calcium-sensing receptors (CASR) in the kidneys and parathyroid $[9,10]$. Furthermore, elevated levels of tumor necrosis factor (TNF-a) have also been 
associated with hypocalcemia. Chernow et al. [11], reported an association between hypocalcemia and prolonged duration in the intensive care unit (ICU), as well as an increase in mortality. However, the diagnosis is complicated by limitations in the interpretation of total plasma calcium concentration. These limitations are primarily the result of the effects of hypoalbuminemia and acid-base balance disorders on total calcium concentration.

Therefore, the measurement of ionized calcium can be critical in determining the actual levels of calcium in an individual's serum. In this way, the recognition of serum electrolytes in patients of the Medical Intensive Care Unit (ICU) may be important, since it could be associated with the severity of the disease or with an increase in mortality and morbidity.

On the other hand, antioxidants have been defined as substances that, when present at low concentrations compared to an oxidizable compound, delay or prevent oxidative, so a large number of exogenous antioxidants have been used.

There are reports that indicate that supplementation with antioxidants helps oxygenation rates, with an increase in glutathione and a greater immune response [12]. This leads to a reduction in hospital stay and in intensive care units, in addition to a decrease in the rates of multi-organ dysfunction and in the rate of morbidity and mortality. However, there are few studies in this regard, which requires greater efforts to reinforce the benefits of antioxidant supplementation.

Based on the above, the purpose of this work was to assess the ionic levels of calcium and ionized magnesium, as well as sodium, potassium and chlorine in patients with septic shock in an intensive care unit, before and after treatment with different antioxidants such as n-acetylcysteine, vitamin C, melatonin, and vitamin $\mathrm{E}$.

\section{Material And Methods}

A case-control clinical trial was conducted. Sixty-five patients $>18$ years of age with septic shock in the last 24 hours, characterized by refractory hypotension and vasopressor requirement, despite sufficient fluid resuscitation $(20 \mathrm{~mL} / \mathrm{kg}$ of colloids or $40 \mathrm{~mL} / \mathrm{kg}$ of crystalloids) to maintain blood pressure were included $\geq 65 \mathrm{mmHg}$ with a lactate $>2 \mathrm{mmol} / \mathrm{L}$ and samples from 129 control patients. The Acute Physiology And Chronic Health Evaluation (APACHE) II and SAPS II scores were determined at admission, as well as the Sequential Organ Failure Assessment (SOFA) score. and MEXSOFA score of organ dysfunction, for each of the sections (Neurological, respiratory, hemodynamic, hepatic, hematological). The MEXSOFA is a validated score in a Mexican cohort that uses the same sections of the SOFA score with two modifications: the $\mathrm{PaO} 2 / \mathrm{FiO} 2$ is changed to the SpO2/FiO2 and the neurological evaluation is eliminated. A MEXSOFA $\leq 9$ points during the first hours of admission to the unit have a mortality of $14.8 \%$, while in patients with a MEXSOFA $\geq 10$ points they have a mortality of $40 \%$.

Signed informed consent from each participant was obtained after full explanation of the purpose and nature of all procedures used in the research study, in accordance with the stipulated in the Declaration of Helsinki, modified by the Tokyo Congress, Japan. The research was approved by the Ethical, Biosecurity and Investigation Committees of the National Institute of Cardiology (Registration number: INCAR-DG-DI-ACEP-039-2021). The protocol was registered (TRIAL REGISTRATION: ClinicalTrials.gov Identifier: NCT 03557229.

Blood samples were taken from all subjects upon admission to the ICU in sterile tubes with EDTA, with heparin, and in tubes with a gel polymer for serum separation. The serum was immediately separated by centrifugation and the determination of the serum electrolytes was performed (Sodium, potassium, chlorine, calcium and magnesium). The blood samples in the heparin-containing blood tubes were kept on ice and analyzed for ionized $\mathrm{Ca}^{2+}$ and $\mathrm{Mg}^{2+}$ levels using an electrolyte analyzer (Nova Biomedical, Waltham, Mass., USA). The Nova can analyze $\mathrm{Na}^{+}, \mathrm{K}^{+}, \mathrm{Cl}^{-}$, ionized $\mathrm{Ca}^{2+}$, and ionized $\mathrm{Mg}^{2+}$. The analyzer provides calculated results for ionized $\mathrm{Ca}^{2+}$, and ionized $\mathrm{Mg}^{2+}$, normalized to a $\mathrm{pH}$ of 7.4, for samples with $\mathrm{pH}$ values between 6.9 and 7.8. It also mathematically adjusts all ionized $\mathrm{Mg}^{2+}$ results for ionized $\mathrm{Ca}^{2+}$ concentrations. A sample volume of $250 \mu \mathrm{l}$ is required for analysis. The analyzer was calibrated with its own calibration solution and was maintained according to the manufacturer's instructions. The results were expressed in millimoles per liter (mmol/L). In addition, blood 
biometry, blood chemistry, liver function tests, c-reactive protein, procalcitonin, and venous and arterial blood gases were analyzed for each study subject.

\section{Antioxidant supplementation}

Patients were randomized and masked into 4 groups, to start treatment in the first 24 hours after admission to the ICU.

1) For the N-acetyl cysteine group, 2 effervescent tablets of $600 \mathrm{mg}$ of $\mathrm{N}$-acetyl cysteine $(1200 \mathrm{mg})$ were administered every 12 hours by oral route or naso-enteral tube for five days.

2) For the melatonin group, melatonin was administered in $5 \mathrm{mg}$ prolonged-release capsules, at a dose of $50 \mathrm{mg}$ (10 capsules) orally or by naso-enteral tube for five days.

3) For the vitamin C group, 1-gram vitamin C tablets were used, which were administered every 6 hours by oral route or nasoenteral tube for five days.

4) For the vitamin E group, vitamin E (d-alpha tocopheryl acetate) capsules of $1200 \mathrm{IU}$ equivalent to 1200 mg were used, which were administered every 24 hours for five days.

After each treatment, the same blood and electrolyte tests were performed.

\section{Statistical Analysis}

The SPSS 21 program was used for statistical analysis. The Student's t test was used to evaluate the differences between the mean values obtained between the groups. An ANOVA test was used to compare plasma ion concentrations. Pearson's chi2 test or Fisher's exact test was used for normal data. The Shapiro-Wilk test was used to determine whether the distributions of the variables were normal. Numerical data are shown as the mean \pm SD, and nominal data were reported as percentages. A logarithmic transformation was applied for the ionized $\mathrm{Mg}^{2+}$ levels due to the non-normal distribution of the variables. The value of $p<0.05$ was considered statistically significant.

\section{Results}

194 subjects were studied, 129 healthy control patients, 14 patients with septic shock without treatment and 51 patients with septic shock under treatment with antioxidants. The mean age of healthy patients was $35.4 \pm 12.04$, which showed a statistically significant difference compared to patients with sepsis without treatment $73.0 \pm 10.49(p=0.000)$ and with treatment $64.16 \pm 17.38(p=0.000)$, being older in these last two groups; Furthermore, there were no significant differences between the two groups with septic shock with and without treatment $(p=0.096)$. Similarly, in gender and BMI, no statistically significant differences were found between the three study groups. When comparing our two groups with septic shock, we found significant differences in the APACHE II score $(p=0.039)$ and in the malnutrition risk assessment $(p=0.020)$ (Table 1). When comparing only our group of patients with septic shock with the different antioxidant treatments, we did not find significant differences in any parameter. 
Table 1

General characteristics of the study subjects and divided according to treatment

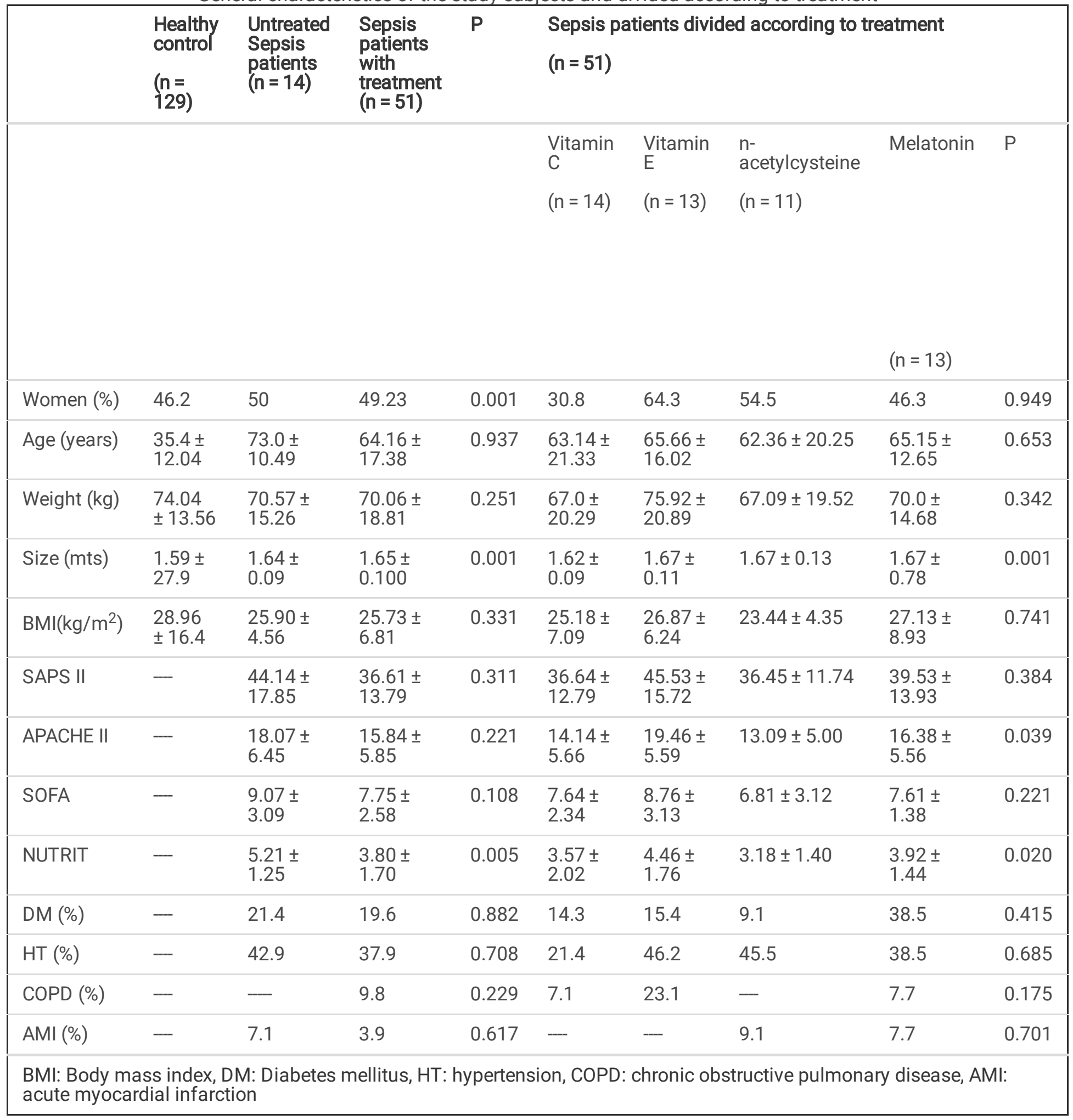

It should be mentioned that, at the time of hospital admission, the most frequent site of infection was the pulmonary system (48.3\%), followed by the gastrointestinal system (17.3\%) (Table 2).

Table 2. Site of infection of subjects with sepsis 


\begin{tabular}{lc}
\hline Pulmonary & $30(48.39)$ \\
Gastrointestinal & $17(27.42)$ \\
Nephrourinary & $7(11.29)$ \\
CNS & $2(3.23)$ \\
Skin & $2(2.33)$ \\
Gastrointestinal and renal & $2(2.33)$ \\
Pulmonary and CNS & $1(1.61)$ \\
Pulmonary and gastrointestinal & $1(1.61)$
\end{tabular}

Subsequently, the ionic levels were analyzed in our 3 study groups: controls, patients with sepsis under treatment, and patients with sepsis without treatment. (Table 3). According to the results, we found significant differences when comparing the plasma ionic levels of $\mathrm{K}^{+}, \mathrm{Ca}^{2+}$ and $\mathrm{Mg}^{2+}$ between the control group versus in both groups with sepsis at the time of hospital admission. At the end of 48 hours under treatment with the different antioxidant drugs, we observed significant differences in all plasma ion values of patients with sepsis compared to controls, except for chlorine levels.

Table 3. Ionic levels at hospital admission and discharge.

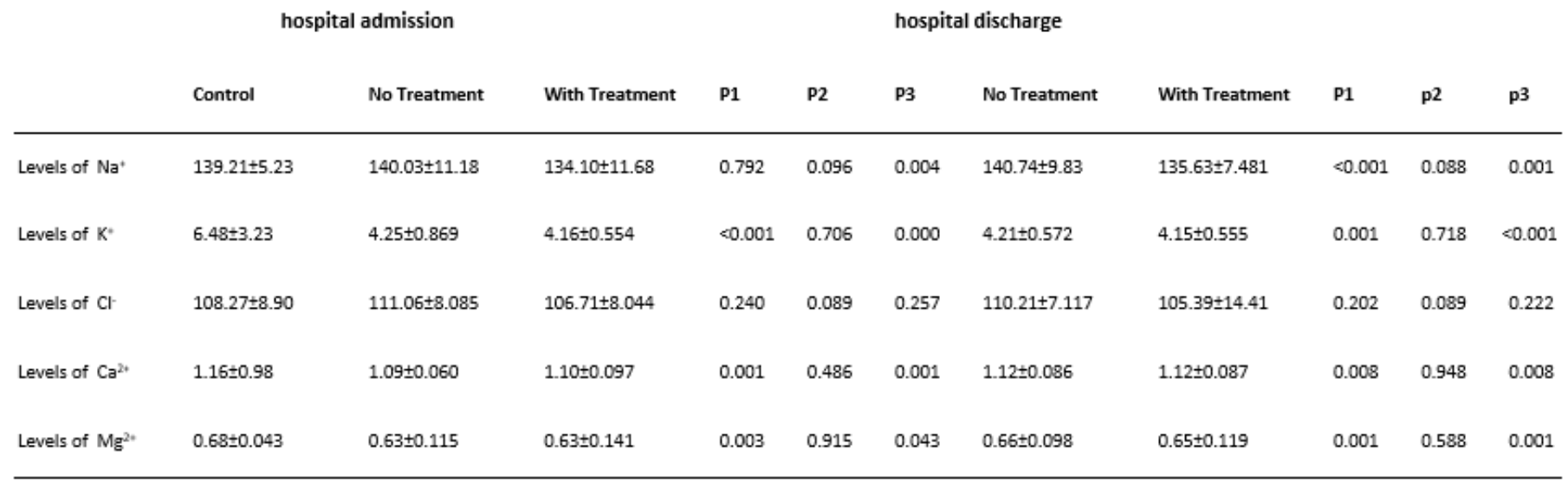

\footnotetext{
P1: control vs sepsis without treatment

P2. Sepsis without treatment vs sepsis with treatment

P3. control vs sepsis with treatment
}

When performing the analysis comparing only the septic shock groups, with and without antioxidant treatment, we did not find statistically significant differences, at the beginning and end of the treatment, in the plasma levels of the study ions. In the same way, ionic levels were compared between the groups under treatment with the different antioxidants, and between the patients with each one of the antioxidants, before and after it (Table 4); however, we did not find a significant difference either. 
Table 4

Plasma ion levels at admission (initial) and after of treatment (final)

\begin{tabular}{|c|c|c|c|c|c|c|}
\hline & \multirow{2}{*}{$\begin{array}{l}\text { Untreated sepsis } \\
\text { patients } \\
(n=14)\end{array}$} & \multicolumn{5}{|c|}{ Patients with sepsis and with treatment } \\
\hline & & $\begin{array}{l}\text { Vitamin C } \\
(n=14)\end{array}$ & $\begin{array}{l}\text { Vitamin } E \\
(n=13)\end{array}$ & $\begin{array}{l}\mathrm{n} \text { - } \\
\text { acetylcisteine } \\
(\mathrm{n}=11)\end{array}$ & $\begin{array}{l}\text { Melatonin } \\
(n=13)\end{array}$ & $\mathrm{p}$ \\
\hline $\mathrm{Na}+$ initial & $140.03 \pm 11.18$ & $\begin{array}{l}135.26 \pm \\
10.11\end{array}$ & $\begin{array}{l}131.98 \pm \\
15.58\end{array}$ & $134.41 \pm 6.54$ & $\begin{array}{l}134.70 \pm \\
13.08\end{array}$ & 0.504 \\
\hline $\mathrm{Na}+$ final & $140.84 \pm 9.83$ & $137.48 \pm 8.54$ & $135.57 \pm 6.98$ & $135.55 \pm 6.37$ & $133.75 \pm 7.97$ & 0.232 \\
\hline p & 0.828 & 0.269 & 0.498 & 0.591 & 0.759 & \\
\hline $\mathrm{K}+$ initial & $4.25 \pm 0.86$ & $4.23 \pm 0.61$ & $4.20 \pm 0.61$ & $4.08 \pm 0.62$ & $4.12 \pm 0.51$ & 0.956 \\
\hline$K+$ final & $4.21 \pm 0.57$ & $4.31 \pm 0.30$ & $4.16 \pm 0.66$ & $4.01 \pm 0.70$ & $4.09 \pm 0.52$ & 0.700 \\
\hline $\mathbf{p}$ & 0.890 & 0.618 & 0.755 & 0.725 & 0.898 & \\
\hline Cl-initial & $111.06 \pm 8.08$ & $108.34 \pm 7.24$ & $104.27 \pm 9.63$ & $105.93 \pm 4.26$ & $108.05 \pm 8.88$ & 0.264 \\
\hline Cl- final & $110.21 \pm 7.11$ & $\begin{array}{l}101.84 \pm \\
26.65\end{array}$ & $107.26 \pm 4.97$ & $105.85 \pm 4.62$ & $106.94 \pm 5.65$ & 0.588 \\
\hline p & 0.712 & 0.314 & 0.406 & 0.953 & 0.668 & \\
\hline $\mathrm{Ca} 2+$ initial & $1.09 \pm 0.06$ & $1.12 \pm 0.82$ & $1.08 \pm 0.13$ & $1.08 \pm 0.06$ & $1.12 \pm 0.10$ & 0.622 \\
\hline $\mathrm{Ca} 2+$ final & $1.12 \pm 0.08$ & $1.11 \pm 0.11$ & $1.13 \pm 0.08$ & $1.12 \pm 0.08$ & $1.12 \pm 0.05$ & 0.965 \\
\hline p & 0.224 & 0.620 & 0.148 & 0.162 & 0.976 & \\
\hline $\begin{array}{l}\text { Mg2+ } \\
\text { initial }\end{array}$ & $0.63 \pm 0.11$ & $0.60 \pm 0.19$ & $0.63 \pm 0.11$ & $0.61 \pm 0.09$ & $0.66 \pm 0.13$ & 0.868 \\
\hline Mg2 + final & $0.66 \pm 0.09$ & $0.65 \pm 0.12$ & $0.67 \pm 0.11$ & $0.62 \pm 0.13$ & $0.63 \pm 0.10$ & 0.876 \\
\hline $\mathrm{p}$ & 0.221 & 0.378 & 0.330 & 0.804 & 0.487 & \\
\hline
\end{tabular}

Despite not finding significant differences in our patients with sepsis and treatment, we were able to observe a physiological response. In patients treated with vitamin $\mathrm{C}$, an increase in the levels of $\mathrm{Na}^{+}, \mathrm{K}^{+}$and $\mathrm{Mg}^{2+}$ was observed, as well as a decrease in the post-treatment levels of $\mathrm{Cl}^{-}$. When comparing these values with the control group, we found a statistically significant difference in all the aforementioned ions $(p \leq 0.001)$. In patients post-treated with vitamin $E$, we observed an increase in the levels of $\mathrm{Na}+, \mathrm{Cl}^{-}, \mathrm{Ca}^{2+}$ and $\mathrm{Mg}^{2+}$. When compared with our control group, ionized calcium presented a significant difference before treatment $(p=0.013)$, but after treatment, this difference was lost $(p=0.378)$; in the case of chlorine, there were no differences versus control before and after treatment. For patients treated with n-acetylcysteine, the most important parameter was ionized calcium, with an increase after treatment. When compared to control patients, there was a significant difference before treatment $(p=0.008)$, but it was lost after treatment $(p=0.129)$. In the case of treatment with melatonin, the most important differences were observed in chlorine and magnesium, since both decreased after treatment, however, only magnesium had a significant difference when compared to the control group, before and after treatment. Subsequently, we made a correlation between the ionic levels before and after the treatment according to the site of infection with respect to the control subjects (Table 5). For patients with lung infection, there was a significant difference in the pretreatment $\mathrm{K}^{+}(\mathrm{p}=0.038)$ and $\mathrm{Mg}^{2+}$ pretreatment $(\mathrm{p}=0.039)$ and post treatment $(\mathrm{p}<0.001)$ values. In patients with urinary tract infection, an increase in calcium levels was found after treatment $(p=0.047)$ and in patients with pulmonary + CNS + gastrointestinal infection there was a significant difference in pretreatment magnesium levels $(p=0.028)$. 
Table 5

Correlation between ionic levels according to the site of infection between cases vs controls

\begin{tabular}{|c|c|c|c|c|c|c|c|c|c|c|}
\hline & $\begin{array}{l}\mathrm{Na}+ \\
\text { initial }\end{array}$ & $\begin{array}{l}\mathrm{Na}+ \\
\text { final }\end{array}$ & $\begin{array}{l}\text { K+ } \\
\text { initial }\end{array}$ & $\begin{array}{l}K+ \\
\text { final }\end{array}$ & $\begin{array}{l}\mathrm{Cl}- \\
\text { initial }\end{array}$ & $\begin{array}{l}\mathrm{Cl}- \\
\text { final }\end{array}$ & $\begin{array}{l}\text { Ca2+ } \\
\text { initial }\end{array}$ & $\begin{array}{l}\mathrm{Ca} 2+ \\
\text { final }\end{array}$ & $\begin{array}{l}\mathrm{Mg} 2+ \\
\text { initial }\end{array}$ & $\begin{array}{l}\mathrm{Mg} 2+ \\
\text { final }\end{array}$ \\
\hline Pulmonary $(n=26)$ & 0.616 & 0.266 & 0.038 & 0.457 & 0.657 & 0.443 & 0.845 & 0.257 & 0.039 & $<0.001$ \\
\hline $\begin{array}{l}\text { Pulmonary + CNS ( } \\
=1)\end{array}$ & 0.315 & 0.933 & 0.932 & 0.780 & 0.114 & 0.369 & 0.431 & 0.788 & 0.204 & 0.391 \\
\hline $\begin{array}{l}\text { Gastrointestinal }(\mathrm{n}= \\
17)\end{array}$ & 0.461 & 0.517 & 0.280 & 0.936 & 0.835 & 0.090 & 0.916 & 0.732 & 0.432 & 0.004 \\
\hline Nephrourinary $(n=7)$ & 0.530 & 0.671 & 0.523 & 0.265 & 0.241 & 0.881 & 0.109 & 0.047 & 0.183 & 0.793 \\
\hline $\begin{array}{l}\text { Pulmonary }+ \\
\text { Gastroint }(n=1)\end{array}$ & 0.927 & 0.899 & 0.054 & 0.350 & 0.316 & 0.840 & 0.845 & 0.788 & 0.359 & 0.031 \\
\hline $\operatorname{SNC}(n=2)$ & 0.447 & 0.939 & 0.425 & 0.460 & 0.407 & 0.231 & 0.664 & 0.919 & 0.744 & 0.872 \\
\hline $\begin{array}{l}\text { Skin + Soft tissue ( } \\
=2)\end{array}$ & 0.705 & 0.847 & 0.357 & 0.069 & 0.740 & 0.922 & 0.790 & 0.983 & 0.816 & 0.277 \\
\hline $\begin{array}{l}\text { Pulm + CNS + Gastro } \\
(n=2)\end{array}$ & 0.240 & 0.888 & 0.150 & 0.893 & 0.449 & 0.555 & 0.731 & 0.430 & 0.028 & 0.112 \\
\hline
\end{tabular}

Finally, the ionic levels were analyzed according to the SOFA score, categorized as mild, moderate and severe, in pretreatment and post-treatment (Table 6). We found a progressive increase in ionic levels from mild to severe of $\mathrm{Na}^{+}, \mathrm{K}^{+}$and $\mathrm{Cl}^{-}$, both pre-treatment and post-treatment; and decreased in ionized calcium and magnesium prior to treatment. In patients with severe SOFA score, after treatment, we found a significant increase in the levels of chlorine $(p=0.008)$ and ionized magnesium $(p=0.001)$.

Table 6

Ionic levels according to the SOFA score

\begin{tabular}{|lllll|}
\hline & Mild & Moderate & Severe & P \\
\hline $\mathrm{Na}+$ Pretreatment & $134.70 \pm 7.05$ & $133.66 \pm 11.36$ & $137.36 \pm 12.74$ & 0.472 \\
\hline $\mathrm{Na}+$ Post treatment & $140.92 \pm 9.26$ & $135.55 \pm 9.33$ & $176.10 \pm 20.68$ & 0.520 \\
\hline $\mathrm{K}+$ Pretreatment & $3.64 \pm 0.42$ & $4.21 \pm 0.51$ & $4.24 \pm 0.73$ & 0.129 \\
\hline $\mathrm{K}+$ Post treatment & $3.99 \pm 0.47$ & $4.13 \pm 0.57$ & $4.23 \pm 0.55$ & 0.615 \\
\hline $\mathrm{Cl}$ - Pretreatment & $104.78 \pm 0.03$ & $107.34 \pm 0.08$ & $108.47 \pm 0.10$ & 0.628 \\
\hline $\mathrm{Cl}$ - Post treatment & $89.04 \pm 4.36$ & $107.94 \pm 6.75$ & $107.81 \pm 5.02$ & 0.008 \\
\hline $\mathrm{Ca} 2+$ Pretreatment & $1.12 \pm 0.03$ & $1.09 \pm 0.08$ & $1.10 \pm 0.10$ & 0.796 \\
\hline $\mathrm{Ca} 2+$ Post treatment & $1.12 \pm 0.02$ & $1.11 \pm 0.09$ & $1.13 \pm 0.08$ & 0.695 \\
\hline $\mathrm{Mg} 2+$ Pretreatment & $0.64 \pm 0.14$ & $0.63 \pm 0.01$ & $0.62 \pm 0.12$ & 0.974 \\
\hline $\mathrm{Mg} 2+$ Post treatment & $0.53 \pm 0.06$ & $0.62 \pm 0.09$ & $0.70 \pm 0.12$ & 0.001 \\
\hline
\end{tabular}

\section{Discussion}

In this work we analyze plasma ionic levels in patients with septic shock before and after treatment with different antioxidants. After a treatment with 4 types of antioxidants ( -acetyl cysteine, melatonin, vitamin $\mathrm{C}$ and vitamin $\mathrm{E}$, we found a change in ionic levels, mainly in ionized magnesium. 
Different studies have tried to establish the electrolyte alterations associated with septic shock, particularly in the length of stay in an ICU, however, the studies are still very scarce.

There are reports where $\mathrm{Mg}^{2+}$ deficiency, together with other electrolyte abnormalities, coexists in up to $40 \%$ of patients [13]. Various factors can contribute to hypomagnesemia in patients with septic shock, such as: decreased absorption caused by impaired gastrointestinal activity, malnutrition, diabetes mellitus, hypokalemia and hypocalcemia [14], hyperaldosteronism, renal tubular disorder, use of drugs such as amphotericin, cisplatin, cyclosporine, diuretics, proton pump inhibitors, and aminoglycoside antibiotics of which some are used during the management of septic shock and others may be being applied prior to septic shock due to cancer or other conditions.

Thus, several reports indicate that hypomagnesemia is associated with a higher mortality rate $[13,15,16]$. In our study, we found low levels of magnesium compared to control subjects in both groups of patients with sepsis; After treatment with different antioxidants, there was an increase in the serum levels of ionized magnesium, however, these values did not reach the levels of the control subjects. The presence of hypomagnesemia can lead to neurological disorders such as diffuse muscle spasms, lethargy, ataxia, nystagmus, twitching, tetany, or seizures. At the muscular level, there may be weakness of the respiratory muscles, hypoventilation, dysphagia and dysphonia; while at the cardiovascular level there may be a prolongation of the P-R and Q-T segments, atrial and ventricular arrhythmias, as well as congestive heart failure. On the other hand, we also observed alterations in the levels of other serum electrolytes such as sodium, potassium and calcium. There are reports that indicate that the decrease in magnesium levels may be accompanied by a reduction in the levels of $\mathrm{K}^{+}$ (hypokalemia) and $\mathrm{Ca}^{2+}$ (hypocalcemia) $[17,18]$. This is because part of calcium metabolism is controlled by the activity of parathyroid hormone (PTH), which seems to be the site of action of magnesium for modulation of calcium balance, since serum magnesium deficiency inhibits the action of PTH in bone, directly preventing calcium release [19, 20]; furthermore, PTH secretion is prevented, since magnesium is a cofactor of the adenylate cyclase enzyme in parathyroid tissue. It has been observed that when hypokalemia occurs, there is the presence of hypomagnesemia in $40 \%$; Likewise, when hypocalcemia is present, hypomagnesemia is present in $22 \%$. [17, 20,21]. On the other hand, when there is a decrease in potassium levels (hypokalemia), it is known that $\mathrm{Mg}^{2+}$ participates in the flow of $\mathrm{Na}^{+}$and $\mathrm{K}^{+}$in the cell membrane, since it acts as a cofactor in the Na-K ATPase, generating an electrochemical gradient and therefore an alteration in the membrane potential that can cause changes in excitability and / or irritability at the neuromuscular level.

Our results show a clear decrease in the serum levels of $\mathrm{Na}^{+}, \mathrm{K}^{+}$and $\mathrm{Ca}^{2+}$ with respect to the control subjects. In the different treatments with antioxidants, we found an increase in the levels of these electrolytes despite not finding a statistically significant increase. These differences were independent of the type of treatment given. This may be due to different reasons, including the number of patients with septic shock, the time between the initial and final sampling, and therefore the time of treatment with antioxidants. However, despite the foregoing, a physiologically important change was observed in the serum levels of the studied ions. Therefore, it is important to correct magnesium levels, to maintain adequate levels mainly of calcium and potassium in patients with septic shock.

Finally, when carrying out the analysis of the electrolytes studied before and after the treatment with antioxidants, according to the SOFA score, an important change was observed mainly in the subjects with severe scores in $\mathrm{Na}^{+}$and $\mathrm{Mg}^{2+}$ levels. This indicates that, the greater the severity of the damage, the antioxidant therapy, regardless of what it is, causes an improvement in the patient, mainly in the levels of magnesium, which, as mentioned above, is an ion that participates in the regulation of other electrolytes and that can help improve the patient's condition.

This study leads to propose that in patients admitted with septic shock, medical management should consider, in addition to standard therapy, antioxidant therapy and specific electrolyte monitoring. The importance of determining magnesium in the basal state allows defining the deficit, which leads to septic shock. The determination of ionized magnesium could be a useful biomarker to include during the study and follow-up of patients in extreme severity 


\section{Conclusion}

Serum levels of ionized $\mathrm{Na}^{+}, \mathrm{K}^{+}, \mathrm{Cl}^{-}$and $\mathrm{Ca}^{2+}$ and $\mathrm{Mg}^{2+}$ were analyzed in control patients with septic shock in an intensive care unit. In patients with septic shock, there is a decrease in the serum levels of ionized $\mathrm{Na}^{+}, \mathrm{K}^{+}, \mathrm{Cl}^{-}$and $\mathrm{Ca}^{2+}$ and $\mathrm{Mg}^{2+}$. Antioxidant treatment as an adjunct to the standard management of patients with septic shock increases the electrolyte deficit. The correction of the magnesium deficit also leads to an increase in serum calcium and potassium levels.

This preliminary result makes it possible to propose multicenter clinical trials with a greater number of cases to confirm the importance of monitoring and surveillance of these ions in the comprehensive therapy of septic shock.

\section{Declarations}

Ethics approval and consent to participate: Signed informed consent from each participant was obtained after full explanation of the purpose and nature of all procedures used in the research study, in accordance with the stipulated in the Declaration of Helsinki, modified by the Tokyo Congress, Japan. The research was approved by the Ethical, Biosecurity and Investigation Committees of the National Institute of Cardiology (Registration number: INCAR-DG-DI-ACEP-039-2021). The protocol was registered (TRIAL REGISTRATION: ClinicalTrials.gov Identifier: NCT 03557229.

Consent of publication: Not applicable

Availability of data and materials: All data generated or analysed during this study are included in this published article.

Competing of Interest: The authors declare no conflict of interest.

Funding: This research did not receive any specific grant from funding agencies in the public, commercial, or not-for-profit sectors.

\section{Authors' contributions}

AAA: Design of the work and interpretation of data and helped draft the manuscript. MES: Participated in the study design and manuscript revision. GCA: Assistant in the collection and analysis of samples. JFG: Assistant in the collection and analysis of samples. RCS: Selection and determination of patients. IPT: Interpretation of data. CHG: Interpretation of data and manuscript revision. YTP: Sample processing. GFA: Sample processing. RGA: Strategy design and drafted manuscript.

All authors read and approved the final manuscript.

Acknowledgments: We thank the participants of this study.

\section{References}

1. - Angus DC, Linde-Zwirble WT, Lidicker J, Clermont G, Carcillo J, Pinsky MR. Epidemiology of severe sepsis in the United States: analysis of incidence, outcome, and associated costs of care. Crit Care Med. 2001;29(7):1303-10.

2. Kumar S, Honmode A, Jain S, Bhagat V. Does magnesium matter in patients of Medical Intensive Care Unit: A study in rural Central India. Indian J Crit Care Med. 2015;19:379-83.

3. Guérin C, Cousin C, Mignot F, Manchon M, Fournier G. Serum and erythrocyte magnesium in critically ill patients. Intensive Care Med. 1996;22:724-7.

4. Guerrera MP, Volpe SL, Mao JJ. Therapeutic uses of magnesium. Am Fam Physician. 2009;80:157-62.

5. Pérez-González E, Santos-Rodríguez F, Coto-García E. Homeostasis del magnesio. Etiopatogenia, clínica y tratamiento de la hipomagnesemia. A propósito de un caso Nefrología. 2009;29(6):518-24. 
6. Taylor B, Sibbald WJ, Edmonds MW, Holliday RL, Williams C. Ionized hypocalcemia in critically ill patients with sepsis. Can J Surg. 1978;21(5):429-33.

7. Zaloga GP, Chernow B. The multifactorial basis for hypocalcemia during sepsis. Studies of the parathyroid hormonevitamin D axis. Ann Intern Med. 1987;107(1):36-41.

8. Yeste D, Campos A, Fábregas A, Soler L, Mogas E, Clemente M. Patología del metabolismo del calcio. Protoc Diagn Ter Pediatr. 2019;1:217-37.

9. Canaff L, Hendy GN. Calcium-sensing receptor gene transcription is up-regulated by the proinflammatory cytokine, interleukin-1beta. Role of the NF-kappaB PATHWAY and kappaB elements. J Biol Chem. 2005;280(14):14177-88.

10. Zaloga GP. Ionized hypocalcemia during sepsis. Crit Care Med. 2000;28(1):266-8.

11. Chernow B, Zaloga G, McFadden E, Kotler M, Rainey TG. Hypocalcemia in critically ill patients. Crit Care Med. 1982;10(12):848-51.

12. Prauchner CA. Oxidative stress in sepsis: Pathophysiological implications justifying antioxidant co-therapy. Burns. 2017;43(17):271-485.

13. Safavi M, Honarmand A. Admission hypomagnesemia - Impact on mortality or morbidity in critically ill patients. Middle East J Anaesthesiol. 2007;19:645-60.

14. Huijgen HJ, Soesan M, Sanders R, Mairuhu WM, Kesecioglu J, Sanders GT. Magnesium levels in critically ill patients. What should we measure? Am J Clin Pathol. 2000;114:688-95.

15. Limaye CS, Londhey VA, Nadkart MY, Borges NE. Hypomagnesemia in critically ill medical patients. J Assoc Physicians India. 2011;59:19-22.

16. Soliman HM, Mercan D, Lobo SS, Mélot C, Vincent JL. Development of ionized hypomagnesemia is associated with higher mortality rates. Crit Care Med. 2003;31:1082-7.

17. Salem M, Muñoz R, Chernow B. Hypomagnesemia in critical illness. Crit Care Clin. 1991;17:225-52.

18. Wbang R, Oei TO, Alkawa JK, Watanabe A, Vannatta J, Fryer A, Markanich M. Predictors of clinical hypomagnesemia. Hypokalemia, Hypophosphatemia, Hyponatremia, and Hypocalcemia. Arch Intern Med. 1984;1144:1794-6.

19. Klein GL, Wolf SE, Goodman WG, Phillips WA, Herndon DN. The management of acute bone loss in severe catabolism due to burn injury. Horm Res. 1997;48:83-7.

20. Whang R. Flink EB, Dyckner T, Wester PO, Aikawa JK, Ryan MP. Mg depletion as a cause of refractory potassium depletion. Arch Intern Med. 1985;145:1686-9.

21. Mclean R. Magnesium and its therapeutic uses: a review. Am J Med. 1994;96:63-76. 